\title{
Desempenho de cordeiros e estimativa da digestibilidade do amido de dietas com diferentes fontes protéicas
}

\author{
Mário Adriano Ávila Queiroz ${ }^{(1)}$, Ivanete Susin(1), Alexandre Vaz Pires ${ }^{(1)}$, Clayton Quirino Mendes ${ }^{(1)}$, \\ Renato Shinkai Gentil(1), Omer Cavalcanti Almeida(1), Rafael Camargo do Amaral ${ }^{(1)}$ e Gerson Barreto Mourão(1) \\ (1)Escola Superior de Agricultura Luiz de Queiroz, Departamento de Zootecnia, Caixa Postal 09, CEP 13418-900 Piracicaba, SP. \\ E-mail: marioqueiroz@hotmail.com, ivasusin@esalq.usp.br, alvpires@esalq.usp.br, cqmendes@esalq.usp.br, gshinkai@bol.com.br, \\ omercavalcanti@yahoo.com.br, rcamaral@esalq.usp.br, gbmourao@esalq.usp.br
}

\begin{abstract}
Resumo - O objetivo deste trabalho foi avaliar a influência de fontes protéicas sobre desempenho, características da carcaça e da carne de cordeiros confinados, e estimar a digestibilidade do amido de rações com alta proporção de grãos. Foram distribuídos 28 cordeiros Santa Inês, em blocos completos ao acaso, de acordo com o peso vivo e a idade, no início do experimento. As fontes protéicas foram os farelos de: soja, amendoim, canola e algodão, em dietas isonitrogenadas com $90 \%$ de concentrado e $10 \%$ de volumoso (feno de coast-cross). Na determinação da digestibilidade, foram utilizados quatro borregos em delineamento experimental em quadrado latino 4x4, e a digestibilidade do amido foi estimada a partir do teor de amido fecal. Não houve diferenças ( $\mathrm{p}>0,05)$ quanto ao consumo de matéria seca, ganho de peso vivo médio, conversão alimentar, características da carcaça e da carne, entre as fontes protéicas avaliadas. A digestibilidade do amido apresentou coeficiente de determinação de $93 \%$. Independentemente da fonte protéica utilizada, o teor de amido nas fezes é um indicador eficiente na estimativa da digestibilidade do amido de dietas com alta proporção de concentrado para cordeiros.
\end{abstract}

Termos para indexação: amido fecal, características da carcaça, características da carne, ovinos.

\section{Lamb performance and estimation of starch digestibility of diets with different protein sources}

\begin{abstract}
The objective of this work was to evaluate the influence of protein sources on feedlot lambs performance, carcass and meat characteristics, and to estimate starch digestibility of high grain diets. Twenty-eight Santa Inês ram lambs were selected in a complete randomized block design, according to body weight and age in the beginning of the experiment. Protein sources were the following meals: soybean, peanut, canola, and cottonseed in isonitrogenous diets with $90 \%$ concentrate and $10 \%$ roughage (coast-cross hay). Four ram lambs $(48 \mathrm{~kg})$ were used to determine starch digestibility in a $4 \mathrm{x} 4$ latin square design, and starch digestibility was estimated by fecal concentration of starch. There were no differences $(p>0.05)$ for dry matter intake, average daily gain, feed conversion, carcass characteristics and meat quality, among the protein sources evaluated. Determination coefficient for starch digestibility was $93 \%$. Fecal starch content is an accurate indicator of the starch digestibility estimation in lambs feeding high grain diets, independently of the protein source used.
\end{abstract}

Index terms: fecal starch, carcass characteristics, meat characteristics, sheep.

\section{Introdução}

O farelo de soja é a principal "commodity" agrícola utilizada como fonte protéica na nutrição de monogástricos e ruminantes, e também utilizado na alimentação humana. Além disso, com a elevação dos preços de derivados de petróleo, o farelo de soja se tornará uma opção cada vez mais atraente para utilização em produtos industriais de alto valor agregado, o que cria a necessidade de se buscar fontes protéicas alternativas para a alimentação animal. Segundo Goes et al. (2004), o farelo de amendoim apresenta em média $50 \%$ de proteína bruta de alta degradabilidade ruminal $(85,2 \%)$ e taxa de passagem de $5 \%$ por hora. Apesar de seu elevado teor de proteína, esse farelo apresenta baixos teores de lisina $(8,3 \%)$ e metionina $(2,9 \%)$, em relação aos farelos comumente utilizados na nutrição de ruminantes. Segundo o National Research Council (2001), o farelo de canola possui perfil de aminoácidos comparável ao do farelo de soja, porém, com teores mais baixos de lisina e mais elevados de metionina 
e cistina, e apresenta, em média, $67,3 \%$ de proteína degradável no rúmen, à taxa de passagem de $5 \%$ por hora. Contudo, as pesquisas que avaliaram o desempenho de cordeiros que receberam essas fontes protéicas são escassas, assim como seus efeitos nas características de carcaça e de carne.

Segundo Susin (2003), é possível produzir carne ovina a partir de animais deslanados, com oferta constante e homogênea ao longo do ano, intensificando o sistema de produção e utilizando dietas com até $90 \%$ de concentrado.

Rações com alto teor de concentrado apresentam elevada concentração de carboidratos não fibrosos, principalmente o amido. Quando os grãos são a maior fonte de amido das dietas, a concentração desse nutriente, nas fezes em novilhos confinados, pode ser utilizada como indicador da digestibilidade do amido no trato digestivo total. A estimativa da digestibilidade do amido, pelo seu teor nas fezes, tem sido utilizada para avaliar grãos processados em confinamento de bovinos, uma vez que a perda de amido nas fezes é significativa nesses ruminantes (Zinn et al., 2002). Embora sejam conhecidas as diferenças no comportamento alimentar entre bovinos e ovinos, poucos trabalhos avaliam a eficiência de utilização ou as perdas de nutrientes nas fezes dos pequenos ruminantes.

Segundo McDonald et al. (1981), os ovinos são mais eficientes na mastigação e ruminação do que os bovinos, pois reduzem grãos inteiros em tamanho similar ao grão moído. Entretanto, Hart \& Glimp (1991), ao avaliar os efeitos metabólicos do fornecimento do grão de milho inteiro ou moído peletizado, para ovinos alimentados com 90\% de concentrado, verificaram produção de ácidos graxos de cadeia curta $12 \%$ superior à dieta com milho moído, em relação ao grão inteiro.

O objetivo deste trabalho foi avaliar a influência de fontes protéicas sobre o desempenho, características da carcaça e da carne de cordeiros confinados, e estimar a digestibilidade do amido de rações com alta proporção de grãos.

\section{Material e Métodos}

O experimento foi realizado no Sistema Intensivo de Produção de Ovinos e Caprinos, do Departamento de Zootecnia da Escola Superior de Agricultura Luiz de Queiroz, Piracicaba, SP, no segundo semestre de 2006.

$\mathrm{Na}$ avaliação de desempenho e características de carcaça, foram utilizados 28 cordeiros da raça Santa Inês - peso médio inicial de $20 \pm 2 \mathrm{~kg}$ e idade inicial média de $75 \pm 5$ dias - confinados em baias individuais com cocho, bebedouro e piso de concreto. Os animais foram everminados e vacinados contra clostridioses antes do início do experimento. O período experimental foi de 56 dias. $\mathrm{O}$ delineamento experimental utilizado foi o de blocos completos ao acaso, determinados segundo o peso e a idade inicial dos animais, com quatro tratamentos e sete repetições.

As dietas foram isonitrogenadas $-16 \%$ de proteína bruta -, formuladas pelo sistema "Small Ruminant Nutrition System" (Cannas et al., 2004), versão 1.8 .1 , e constituídas de $10 \%$ de volumoso (feno de coast-cross) e $90 \%$ de concentrado na matéria seca, e diferiu quanto à fonte principal de proteína: farelo de soja, farelo de amendoim, farelo de canola ou farelo de algodão, constituindo os tratamentos experimentais (Tabela 1).

A matéria seca, matéria mineral, extrato etéreo e proteína bruta das fontes protéicas foram determinados segundo Association of Official Analytical Chemists (1990). As análises de fibra em detergente neutro e fibra em detergente ácido foram realizadas de acordo com Van Soest et al. (1991). As análises de amido foram realizadas por meio de hidrólise enzimática do amido da amostra e determinação da glicose resultante (Poore et al., 1989). Os teores de pectina foram determinados segundo Gorshkova et al. (1996). A composição química das fontes protéicas está apresentada na Tabela 2.

As dietas foram fornecidas à vontade, a cada dois dias na forma de ração total, em cochos de madeira, e as sobras foram pesadas semanalmente para a estimativa do consumo diário de matéria seca por animal. Os animais foram pesados semanalmente para determinação do ganho de peso médio diário.

O peso estabelecido de abate dos animais foi de $38 \mathrm{~kg}$, e o abate realizado após jejum alimentar de 14 horas. Para avaliar as características da carcaça, após a retirada da pele e evisceração, a carcaça foi pesada e, em seguida, colocada em câmara fria a $4^{\circ} \mathrm{C}$ 
por 24 horas. Após esse período, foi obtido o peso da carcaça fria e, sem seguida, ela foi seccionada longitudinalmente. Nas duas meias carcaças, foram medidas a gordura subcutânea, utilizando-se paquímetro, e a área de olho de lombo no músculo longissimus, exposto entre a $12^{\mathrm{a}}$ e $13^{\mathrm{a}}$ costela, a qual foi desenhada em papel vegetal e, posteriormente, mensurada por meio de planímetro graduado em $\mathrm{cm}^{2}$.

Após serem descongeladas por 48 horas a $2^{\circ} \mathrm{C}$, as amostras do longissimus foram pesadas em bandejas de alumínio, em balança semi-analítica, para obtenção do peso inicial e, em seguida, foram colocadas em forno elétrico a $170^{\circ} \mathrm{C}$, para determinação da perda de água por cocção (PAC). A temperatura interna dos músculos na região central foi acompanhada com pares termoelétricos individuais com sonda metálica de perfuração. Os músculos foram retirados do forno quando a temperatura interna atingiu $71^{\circ} \mathrm{C}$ e pesados na mesma balança para obtenção do peso final (American Meat Science Association, 1995).

A força de cisalhamento (FC) foi determinada após o equilíbrio de temperatura das amostras cozidas com a temperatura ambiente. Em seguida, foram retirados seis cilindros de meia polegada de diâmetro de cada amostra utilizando-se um vazador manual no sentido das fibras da carne (American Meat Science Association, 1995). Cada cilindro foi avaliado quanto à resistência de cisalhamento (em quilograma), em aparelho Warner-Bratzler Shear Force. Foi considerado para cada amostra, a média dos valores obtidos nos seis cilindros.

Para avaliar a digestibilidade do amido no trato digestório total, foram utilizados quatro borregos da raça Santa Inês, com peso vivo médio de $48 \pm 5 \mathrm{~kg}$ e com aproximadamente sete meses de idade, em delineamento quadrado latino $4 \times 4$, com 16 observações. Os animais foram alojados em gaiolas para ensaios de metabolismo, providas de cocho e bebedouro. A cada período experimental, os animais foram submetidos a dez dias de adaptação: às gaiolas, às rações e às sacolas coletoras de fezes, e cinco dias para coleta de amostras de fezes, o que correspondeu a um período de 15 dias. A digestibilidade aparente do amido no trato digestório foi determinada por coleta total de fezes, assim como a sua predição segundo as concentrações de nitrogênio, matéria seca e amido fecal em percentagem de matéria seca, conforme Zinn et al. (2007).

Os dados foram submetidos à análise de variância e, quando significativas, as médias foram comparadas pelo teste Tukey, a 5\% de probabilidade utilizando-se MIXED (SAS Institute, 2003). Os teores de nitrogênio fecal, amido fecal, matéria seca fecal e digestibilidade aparente do amido no trato digestório total foram submetidos à análise de regressão.

Tabela 1. Composição das rações experimentais (percentagem de matéria seca).

\begin{tabular}{|c|c|c|c|c|}
\hline \multirow[t]{2}{*}{ Ingrediente } & \multicolumn{4}{|c|}{ Tratamento } \\
\hline & Farelo de soja & Farelo de amendoim & Farelo de canola & Farelo de algodão \\
\hline Milho grão moído (1,4 mm) & 54,0 & 52,8 & 50,7 & 49,3 \\
\hline Polpa cítrica peletizada moída $(0,9 \mathrm{~mm})$ & 18,5 & 18,5 & 18,5 & 18,5 \\
\hline Farelo de soja & 15,0 & - & - & - \\
\hline Farelo de amendoim & - & 16,2 & - & - \\
\hline Farelo de canola & - & - & 18,3 & - \\
\hline Farelo de algodão & - & - & - & 19,7 \\
\hline Mistura mineral ${ }^{(1)}$ & 1,4 & 1,4 & 1,4 & 1,4 \\
\hline Cloreto de amônio & 0,5 & 0,5 & 0,5 & 0,5 \\
\hline Calcário & 0,6 & 0,6 & 0,6 & 0,6 \\
\hline Feno "coast-cross" & 10,0 & 10,0 & 10,0 & 10,0 \\
\hline Total & 100,0 & 100,0 & 100,0 & 100,0 \\
\hline \multicolumn{5}{|l|}{ Nutrientes } \\
\hline Matéria seca & 89,3 & 90,5 & 89,6 & 89,8 \\
\hline Proteína bruta & 16,2 & 15,8 & 16,2 & 15,8 \\
\hline Extrato etéreo & 3,1 & 5,1 & 3,2 & 3,3 \\
\hline Fibra em detergente neutro & 20,0 & 20,3 & 22,8 & 21,6 \\
\hline Amido & 41,0 & 43,0 & 38,6 & 37,7 \\
\hline Energia metabolizável $^{(2)}\left(\mathrm{Mcal} \mathrm{kg}^{-1}\right)$ & 2,9 & 3,0 & 2,8 & 2,8 \\
\hline
\end{tabular}

${ }^{(1)}$ Composição: P, 7,5\%; Ca, 19\%; Mg, 1\%; S, 7\%; Na, 14,3\%; Cl, 21,8\%; Fe, 500 ppm; Cu, 300 ppm; Zn, 4.600 ppm; Mn, 1.100 ppm; I, 80 ppm; Co, 405 ppm; Se, 30 ppm. ${ }^{(2)}$ Estimativa obtida a partir da composição dos ingredientes da biblioteca de alimentos do "Small Ruminant Nutrition System" (Cannas et al., 2004). 


\section{Resultados e Discussão}

O consumo diário de matéria seca e de amido dos borregos foi similar $(p>0,05)$ entre os tratamentos. O mesmo comportamento foi observado para a digestibilidade aparente no trato digestório total da matéria seca e do amido, com média de 73,95 e 99,39\%, respectivamente (Tabela 3). Entretanto, Khan et al. (1997), ao avaliar farelo de soja, farelo de canola e farelo de algodão, em rações com $65 \%$ de concentrado e $13,6 \%$ de proteína bruta na alimentação de cordeiros da raça Afghani, encontraram diferença $(\mathrm{p}>0,05)$ na digestibilidade da matéria seca e da proteína bruta, sendo inferior na dieta com farelo de algodão de 7,8 e 4,2\%, respectivamente.

Neste trabalho, não houve efeito $(p>0,05)$ da concentração de $\mathrm{N}$ nas fezes, na excreção de matéria seca fecal (NF) e na digestibilidade do amido dos ovinos, como verificado por Zinn et al. (2007), em bovinos que receberam rações com alta proporção de grãos. Esses autores observaram, em bovinos, efeito $(p<0,01)$ entre a concentração de $\mathrm{NF}$ e excreção de matéria seca nas fezes - excreção de MS fecal em percentagem de consumo $=93,8-49,7 \mathrm{NF}+$ $8,53 \mathrm{NF}^{2}$ - em que a concentração de NF explicou, aproximadamente, $35 \%$ da variação da excreção de matéria seca nas fezes. A digestibilidade do amido,

Tabela 2. Composição química percentual das fontes protéicas (percentagem de matéria seca).

\begin{tabular}{lrrrr}
\hline Nutriente & \multicolumn{4}{c}{ Fonte protéica } \\
\cline { 2 - 5 } & $\begin{array}{r}\text { Farelo } \\
\text { de soja }\end{array}$ & $\begin{array}{r}\text { Farelo de } \\
\text { amendoim }\end{array}$ & $\begin{array}{r}\text { Farelo de } \\
\text { canola }\end{array}$ & $\begin{array}{r}\text { Farelo de } \\
\text { algodão }\end{array}$ \\
\hline Matéria seca & 90,0 & 96,0 & 90,4 & 92,0 \\
Matéria mineral & 6,7 & 6,0 & 6,2 & 6,6 \\
Proteína bruta & 52,0 & 49,2 & 44,5 & 42,0 \\
Extrato etéreo & 0,6 & 14,2 & 2,3 & 2,4 \\
Fibra em detergente neutro & 11,8 & 14,2 & 28,0 & 22,5 \\
Fibra em detergente ácido & 10,3 & 10,3 & 19,4 & 18,5 \\
Hemicelulose & 1,5 & 4,0 & 8,6 & 4,0 \\
Amido & 3,9 & 11,4 & 4,3 & 1,6 \\
Pectina & 7,8 & 7,5 & 2,9 & 5,8 \\
\hline
\end{tabular}

em percentagem de consumo, foi estimada pela concentração de NF, amido fecal (AF) e amido da dieta (AD), pela equação: $100\{1-[(0,938-0,497 \mathrm{NF}$ $\left.\left.\left.+0,0853 \mathrm{NF}^{2}\right) \mathrm{AF} / \mathrm{AD}\right]\right\}$, que explicou $99 \%$ da variação da digestibilidade do amido.

$\mathrm{O}$ NF não foi bom indicador para se estimar a digestibilidade do amido nos cordeiros neste trabalho, entretanto, o AF foi significativo $(\mathrm{p}<0,01)$ e explicou aproximadamente $89 \%$ da digestibilidade do amido no trato digestório total, apresentado pela equação: 99,9 - 0,612AF. Ao introduzir o teor de amido dietético na equação de regressão para estimar a digestibilidade do amido, verificou-se aumento do coeficiente de determinação de 89 para $93 \%$, e representado pela equação: 100,02 - 26,74(AF/AD).

$\mathrm{Na}$ Figura 1, está representado o valor da digestibilidade do amido no trato digestório total e a estimativa da digestibilidade desse nutriente determinado pela equação. Contudo, somente o teor de amido nas fezes pode ser utilizado como único marcador na estimativa da digestibilidade do amido de rações de ovinos com alta proporção de grãos. Essa forte relação entre o teor de amido fecal e a digestibilidade do amido foi confirmada por Corona et al. (2005), que obtiveram, aproximadamente, 97\% do valor observado em ensaios metabólicos e o valor predito pela análise de regressão em bovinos confinados. O teor de amido nas fezes pode ser utilizado para se estimar a digestibilidade do amido em ovinos, reduzir o custo de análises laboratoriais e ser utilizado como ferramenta para avaliar o manejo nutricional ou o processamento de grãos.

Quase a totalidade do amido das rações experimentais $(99,4 \%)$ foi digerida no trato gastrointestinal (Tabela 3). Segundo Huntington (1994), 92 a 99\% do amido de milho é digerido no trato gastrointestinal de ruminantes, e 5 a $20 \%$ do amido consumido é digerido no intestino delgado.

Tabela 3. Consumo diário de matéria seca e de amido (quilograma por dia), digestibilidade aparente no trato digestório total da matéria seca e do amido (DATT) e concentração de amido fecal de borregos alimentados com rações com diferentes fontes protéicas, em percentagem de matéria seca.

\begin{tabular}{|c|c|c|c|c|}
\hline \multirow[t]{2}{*}{ Variável } & \multicolumn{4}{|c|}{ Tratamentos } \\
\hline & Farelo de soja & Farelo de amendoim & Farelo de canola & Farelo de algodão \\
\hline Consumo de matéria seca & $1,18 \pm 0,11$ & $1,29 \pm 0,11$ & $1,21 \pm 0,11$ & $1,36 \pm 0,11$ \\
\hline Consumo de amido & $0,49 \pm 0,23$ & $0,56 \pm 0,23$ & $0,49 \pm 0,23$ & $0,52 \pm 0,23$ \\
\hline DATT da matéria seca & $76,08 \pm 5,10$ & $73,58 \pm 5,10$ & $75,37 \pm 5,10$ & $70,79 \pm 5,10$ \\
\hline DATT do amido & $99,49 \pm 0,45$ & $99,23 \pm 0,45$ & $99,54 \pm 0,45$ & $99,30 \pm 0,45$ \\
\hline Amido nas fezes & 0,76 & 1,15 & 0,67 & 0,80 \\
\hline
\end{tabular}


Entretanto, Hart \& Glimp (1991), ao avaliar o grão de milho inteiro ou moído peletizado para ovinos alimentados com $90 \%$ de concentrado, obtiveram $85 \%$ de digestibilidade do amido e não observaram diferença $(p>0,05)$ nessa variável e também no consumo de matéria seca, para os diferentes processamentos do grão de milho. Contudo, segundo o National Research Council (2001), o milho quebrado apresenta $85 \%$ de nutrientes digestíveis totais (NDT) e o milho moído, $89 \%$.

As rações utilizadas neste trabalho continham aproximadamente $40 \%$ de amido e milho moído, com tamanho médio de partícula de 1,4 $\mathrm{mm}$ (Tabela 1), e foi constatado que somente $0,84 \%$ desse amido foi eliminado nas fezes (Tabela 3). Em alguns experimentos que avaliaram milho-grão inteiro, quebrado ou moído para ovinos (Hart \& Glimp, 1991; Bolzan et al., 2007), não foi observada diferença significativa no consumo e na digestibilidade da matéria seca. Entretanto, os referidos trabalhos não mencionam a eficiência de utilização do amido, ou seja, as perdas desse nutriente nas fezes.

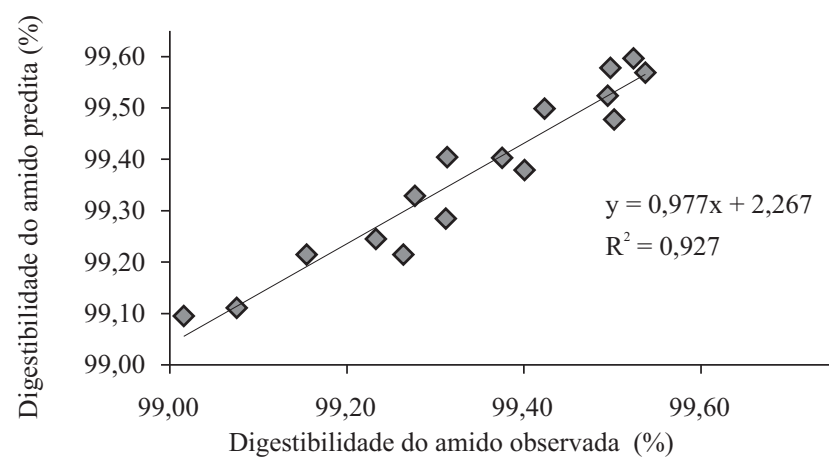

Figura 1. Relação entre a digestibilidade do amido no trato digestório total predita e observada no ensaio de metabolismo.
Não foi observada diferença $(p>0,05)$ no consumo de matéria seca em quilograma por dia, em grama por quilograma de peso vivo metabólico e em percentagem de peso vivo entre os tratamentos (Tabela 4). Comportamento semelhante também foi observado para o consumo de proteína bruta (em quilograma por dia, em grama por quilograma de peso vivo metabólico) dos cordeiros confinados. $\mathrm{O}$ ganho de peso médio diário e a conversão alimentar também não apresentaram diferença, o que demonstra a possibilidade de utilização de qualquer uma das fontes protéicas avaliadas, devendo ser considerado o custo de aquisição e a disponibilidade de mercado.

O ganho de peso médio dos cordeiros entre os tratamentos neste trabalho foi de $310 \mathrm{~g}$ por animal (Tabela 4). Gastaldelo Junior (2007) utilizou a mesma proporção de concentrado e $16 \%$ proteína bruta, em rações com diferentes tamponantes para cordeiros Santa Inês confinados e verificou ganho de peso médio entre os tratamentos de $296 \mathrm{~g}$. Adicionalmente, Urano et al. (2006) avaliaram teores crescentes de soja-grão sobre o desempenho de cordeiros, com semelhante proporção de concentrado ao utilizado neste trabalho, e $18,4 \%$ proteína bruta e verificaram ganho de peso médio entre os tratamentos de $277 \mathrm{~g}$. Entretanto, para o tratamento-controle (sem sojagrão), que apresentou o farelo de soja como principal fonte protéica, foi observado ganho de $298 \mathrm{~g}$ por dia. A maior diferença entre as rações desses trabalhos é a percentagem de milho (70\%), enquanto que no presente trabalho, a percentagem de milho utilizada foi de $52 \%$ (Tabela 1). A substituição parcial do amido por pectina de polpa cítrica pode ter contribuído para melhorar o padrão fermentativo e, possivelmente, maior produção de ácidos graxos de cadeia curta.

Tabela 4. Ganho de peso médio diário, consumo de matéria seca e conversão alimentar de cordeiros alimentados com rações com diferentes fontes protéicas.

\begin{tabular}{|c|c|c|c|c|}
\hline \multirow[t]{2}{*}{ Variável } & \multicolumn{4}{|c|}{ Tratamento } \\
\hline & $\begin{array}{c}\text { Farelo de } \\
\text { soja }\end{array}$ & $\begin{array}{l}\text { Farelo de } \\
\text { amendoim }\end{array}$ & $\begin{array}{c}\text { Farelo de } \\
\text { canola }\end{array}$ & $\begin{array}{c}\text { Farelo de } \\
\text { algodão }\end{array}$ \\
\hline Ganho de peso médio diário $(\mathrm{kg})$ & $0,33 \pm 0,02$ & $0,32 \pm 0,02$ & $0,28 \pm 0,02$ & $0,31 \pm 0,02$ \\
\hline \multicolumn{5}{|l|}{ Consumo de matéria seca: } \\
\hline quilograma por dia & $1,17 \pm 0,04$ & $1,09 \pm 0,04$ & $1,04 \pm 0,04$ & $1,17 \pm 0,04$ \\
\hline grama por quilograma de peso metabólico & $93,20 \pm 0,24$ & $89,30 \pm 0,24$ & $86,80 \pm 0,24$ & $93,70 \pm 0,24$ \\
\hline percentagem de peso corporal & $3,64 \pm 0,04$ & $3,56 \pm 0,04$ & $3,77 \pm 0,04$ & $3,85 \pm 0,04$ \\
\hline \multicolumn{5}{|l|}{ Consumo de proteína bruta: } \\
\hline quilograma por dia & $0,19 \pm 0,03$ & $0,18 \pm 0,03$ & $0,18 \pm 0,03$ & $0,18 \pm 0,03$ \\
\hline grama por quilograma de peso metabólico & $16,60 \pm 0,10$ & $16,30 \pm 0,10$ & $15,90 \pm 0,10$ & $16,60 \pm 0,10$ \\
\hline Conversão alimentar: quilograma de matéria seca ingerida por quilograma de ganho & $3,53 \pm 0,03$ & $3,46 \pm 0,03$ & $3,67 \pm 0,03$ & $3,77 \pm 0,03$ \\
\hline
\end{tabular}


A conversão alimentar foi em média $3,6 \mathrm{~kg}$, e semelhante entre os tratamentos (Tabela 4). A conversão foi próxima aos resultados obtidos por Urano etal.(2006), que variou de 3,4 a $3,7 \mathrm{~kg}$ para cordeiros alimentados com diferentes teores de soja-grão, em rações com $90 \%$ de concentrado. Trabalho semelhante foi realizado por Khan et al. (1997), que avaliaram farelo de soja, farelo de canola e farelo de algodão na alimentação de cordeiros em crescimento e encontraram diferença $(p<0,05)$ no ganho de peso médio entre as fontes protéicas, porém, não obtiveram efeito $(p>0,05)$ no consumo de matéria seca.

Não foi observada diferença $(p>0,05)$ no rendimento de carcaça quente, rendimento de carcaça fria, espessura de gordura e área de olho de lombo entre os tratamentos (Tabela 5). O rendimento de carcaça quente dos cordeiros abatidos com peso vivo médio de $39,5 \mathrm{~kg}$ no presente trabalho foi de $50,6 \%$. Um dos fatores que pode influenciar o rendimento de carcaça é o peso de abate. Rodrigues (2005) obteve rendimento médio de carcaça quente de 49,87\%, ao avaliar diferentes teores de polpa cítrica, em substituição ao milho para cordeiros Santa Inês, alimentados com rações com $90 \%$ de concentrado e abatidos com peso médio de $33,3 \mathrm{~kg}$,

Ponnampalam et al. (2005) suplementaram cordeiros com rações com forragem, farelo de soja, farelo de canola ou farinha de peixe. O peso de abate dos animais foi de $38,8 \mathrm{~kg}$ e não foi observada diferença $(\mathrm{p}>0,05)$ no rendimento de carcaça quente entre os suplementos com farelo de canola ou farelo de soja. Adicionalmente, Kandylis et al. (1999) substituíram o farelo de girassol pelo farelo de algodão, em rações para cordeiros, e não verificaram diferença $(p>0,05)$ no ganho de peso médio e no rendimento de carcaça quente, os quais foram de $0,215 \mathrm{~kg}$ por dia e $55,4 \%$, respectivamente.

A ração com farelo de amendoim apresentou 5,1\% de extrato etéreo na matéria seca (Tabela 1), porém não proporcionou mudança na espessura de gordura das carcaças. Mesmo com rações de alta proporção de concentrado, não ocorreu maior deposição de gordura, devido, provavelmente, ao curto período de confinamento - de 56 dias - e à idade de abate dos animais de aproximadamente 135 dias.

A importância em avaliar a perda de líquidos durante o cozimento está associada à suculência da carne durante a degustação. Segundo Costa et al. (2002), a perda de água por cocção é negativamente correlacionada com a suculência. A perda de água por cocção do músculo longissimus neste trabalho foi de 29,58 a $30,05 \%$ (Tabela 5). Bonagurio et al. (2003), ao utilizar chapa pré-aquecida a $150^{\circ} \mathrm{C}$ até que a temperatura interna da amostra atingisse 72 a $75^{\circ} \mathrm{C}$, para calcular a perda de água por cocção, encontraram valores de 35,8 a 37,1\% para cordeiros da raça Santa Inês. Da mesma forma, Bressan et al. (2001), ao trabalhar com cordeiros das raças Santa Inês e Bergamácia e ao utilizarem o mesmo método, encontraram valores entre 27,2 e $33,1 \%$ de perda de água por cocção. Esses valores estão próximos ao obtido no presente trabalho, que foi de $29,7 \%$.

Além da suculência avaliou-se a maciez da carne dos cordeiros. Essa por sua vez, pode ser analisada por força de cisalhamento ou por ensaios sensoriais (Babiker et al., 1990). A força de cisalhamento do músculo longissimus dos cordeiros foi de 3,7 a $4,2 \mathrm{~kg}$ (Tabela 5). Abularach et al. (1998) definiram como limite máximo $5 \mathrm{~kg}$ de força de cisalhamento para a carne ser considerada macia. $\mathrm{O}$ valor médio da força de cisalhamento obtido neste trabalho foi de $3,95 \mathrm{~kg}$, valor semelhante entre os tratamentos $(\mathrm{p}>0,05)$ e superior ao encontrado por Oliveira et al. (2004) que, ao avaliar a força de cisalhamento do músculo longissimus de ovinos da raça Santa Inês, encontraram valores de 2,73 kg para cordeiro de $38,8 \mathrm{~kg}$, e de $3,55 \mathrm{~kg}$ para machos adultos de $53 \mathrm{~kg}$.

Tabela 5. Características de carcaça e do músculo longissimus de cordeiros alimentados com rações com diferentes fontes protéicas.

\begin{tabular}{|c|c|c|c|c|}
\hline \multirow[t]{2}{*}{ Variável } & \multicolumn{4}{|c|}{ Tratamento } \\
\hline & Farelo de soja & Farelo de amendoim & Farelo de canola & Farelo de algodão \\
\hline Peso de abate $(\mathrm{kg})$ & $40,30 \pm 0,90$ & $39,60 \pm 1,10$ & $38,05 \pm 0,80$ & $40,30 \pm 1,00$ \\
\hline Rendimento de carcaça quente $(\%)$ & $50,60 \pm 0,73$ & $50,40 \pm 0,73$ & $51,30 \pm 0,73$ & $50,30 \pm 0,73$ \\
\hline Rendimento de carcaça fria (\%) & $49,50 \pm 0,83$ & $49,30 \pm 0,83$ & $50,20 \pm 0,83$ & $49,00 \pm 0,83$ \\
\hline Espessura de gordura (mm) & $2,00 \pm 0,12$ & $1,90 \pm 0,12$ & $2,00 \pm 0,12$ & $2,10 \pm 0,12$ \\
\hline Área de olho de lombo $\left(\mathrm{cm}^{2}\right)$ & $14,65 \pm 0,91$ & $13,65 \pm 0,91$ & $14,90 \pm 0,91$ & $13,95 \pm 0,91$ \\
\hline Perda de água por cocção (\%) & $29,67 \pm 3,77$ & $30,05 \pm 3,77$ & $29,58 \pm 3,77$ & $29,63 \pm 3,77$ \\
\hline Força de cisalhamento $(\mathrm{kg})$ & $4,10 \pm 0,81$ & $3,70 \pm 0,81$ & $4,20 \pm 0,81$ & $3,80 \pm 0,81$ \\
\hline
\end{tabular}




\section{Conclusões}

1. As fontes protéicas avaliadas não influenciam o desempenho e as características de carcaça e da carne dos cordeiros confinados.

2. O teor de amido fecal pode ser utilizado para estimar a digestibilidade do amido de rações com alta proporção de grãos, fornecidas para ovinos em crescimento.

\section{Referências}

ABULARACH, M.L.S.; ROCHA, C.E.; FELICIO, P.E. de. Características de qualidade do contra-filé (m. L. dorsi) de touros jovens da raça Nelore. Ciência e Tecnologia de Alimentos, v.18, p.205-210, 1998.

AMERICAN MEAT SCIENCE ASSOCIATION. Research guidelines for cookery, sensory evaluation, and instrumental tenderness of fresh meat. Chicago, 1995. 47p.

ASSOCIATION OF OFFICIAL ANALYTICAL CHEMISTS. Official methods of analysis of the Association of Official Analytical Chemists. $11^{\text {th }}$ ed. Washington, 1990. 1051p.

BABIKER, S.A.; EL KHIDER, I.A.; SHAFIE, S.A. Chemical composition and quality attributes of goat meat and lamb. Meat Science, v.28, p.273-277, 1990.

BOLZAN, I.T.; SANCHEZ, L.M.B.; CARVALHO, P.A.; VELHO, J.P.; LIMA, L.D. de; MORAIS, J.; CADORIN JÚNIOR., R.L. Consumo e digestibilidade em ovinos alimentados com dietas contendo grão de milho moído, inteiro ou tratado com uréia, com três níveis de concentrado. Ciência Rural, v.37, p.229-234, 2007.

BONAGURIO, S.; PÉREZ, J.R.O.; GARCIA, I.F.F.; BRESSAN, M.C.; LEMOS, A.L. da S.C. Qualidade da carne de cordeiros Santa Inês puros e mestiços com Texel abatidos com diferentes pesos. Revista Brasileira de Zootecnia, v.32, p.1981-1991, 2003. (Suplemento 2).

BRESSAN, M.C.; PRADO, O.V.; PÈREZ, J.R.O.; LEMOS, A.L. da S.C.; BONAGURIO, S. Efeito do peso ao abate de cordeiros Santa Inês e Bergamácia sobre as características físico-químicas da carne. Ciência e Tecnologia de Alimentos, v.21, p.293-303, 2001.

CANNAS, A.; TEDESCHI, L.O.; FOX, D.G.; PELL, A.N.; VAN SOEST, P.J. A mechanistic model for predicting the nutrient requirements and feed biological value for sheep. Journal of Animal Science, v. 82, p. 149-169, 2004.

CORONA, L.; RODRIGUEZ, S.; WARE, R.A.; ZINN, R.A. Comparative effects of whole, ground, dry-rolled and steamflaked corn on digestion and growth performance in feedlot cattle. Professional Animal Scientist, v.21, p.200-206, 2005.

COSTA, E.C. da; RESTLE, J.; BRONDANI, I.L.; PEROTTONI, J.; FATURI, C.; MENEZES, L.F.C. de. Composição física da carcaça, qualidade da carne e conteúdo de colesterol do músculo Longissimus dorsi de novillhos Red Angus superprecoces, terminados em confinamento e abatidos com diferentes pesos. Revista Brasileira de Zootecnia, v.31, p.417-428, 2002. (Suplemento 1).
GASTALDElO JUNIOR, A.L. Monensina sódica, bicarbonato de sódio e duas fontes de calcário em rações com alto concentrado para a terminação de cordeiros Santa Inês. 2007. 79p. Dissertação (Mestrado) - Escola Superior de Agricultura Luiz de Queiroz, Piracicaba.

GOES, R.H. de T. e B.; MANCIO, A.B.; VALADARES FILHO, S. de C.; LANA, R de P. Degradação ruminal da matéria seca e proteína bruta, de alimentos concentrados utilizados como suplemento para novilhos. Ciência e Agrotecnologia, v.28, p.167-173, 2004.

GORSHKOVA, T.A.; WYATT, S.E.; SALINIKOV, V.V.; GIBEAUT, D.M.; IBRAGIMOV, M.R.; LOZOVAYA, V.V.; CARPITA, N.C. Cell-wall polysaccharides of developing flax plants. Plant Physiology, v.110, p.721-729, 1996.

HART, S.P.; GLIMP, H.A. Effect of diet composition and feed intake level on diet digestibility and ruminal metabolism in growing lambs. Journal of Animal Science, v.69, p.1636-1644, 1991.

HUNTINGTON, G.B. Ruminant starch utilization progress has been extensive. Feedstuffs, v.66, p.18-43, 1994.

KANDYLIS, K.; NIKOKYRIS, N.P.; DELIGIANNIS, K. Performance of growing-fattening lambs fed diets containing different proportions of cotton seed meal. Journal of the Science of Food and Agriculture, v.79, p.1613-1619, 1999.

KHAN, A.G.; AZIM, A.; NADEEM, M.A.; KHAN, M.A. Effect of growing fattening diets on the growth performance of intensified Afghani lambs. Small Ruminant Research, v.25, p.39-42, 1997.

McDONALD, P.; EDWARDS, R.; GREENHALGH, J. Animal nutrition. $3^{\text {rd }}$ ed. Zaragoza: Acribia, 1981. 518p

NATIONAL RESEARCH COUNCIL. Nutrient requirements of dairy cattle. $7^{\text {th }}$ ed. Washington: National Academy Press, 2001. 381p.

OLIVEIRA, I. de; SILVA, T.J.P. da; FREITAS, M.Q. de; TORTELLY, R.; PAUlinO, F. de O. Caracterização do processo de Rigor Mortis em músculos de cordeiros e carneiros da raça Santa Inês e maciez da carne. Acta Scientiae Veterinariae, v.32, p.25-31, 2004.

PONNAMPALAM, E.N.; EGAN, A.R.; SINCLAIR, A.J.; LEURY, B.J. Feed intake, growth, plasma glucose and urea nitrogen concentration, and carcass traits of lambs fed isoenergetic amounts of canola meal, soybean meal, and fish meal with forage based diet. Small Ruminant Research, v.58, p.245-252, 2005.

POORE, M.H.; ECK, T.P.; SWINGLE, R.S.; THEURER, C.B. Total starch and relative starch availability of feed grains. In: BIENIAL CONFERENCE ON RUMEN FUNCTION, 20., 1989, Chicago. Proceedings. Chicago, 1989. 1 CD-ROM.

RODRIGUES, G.H. Polpa cítrica na ração de cordeiros confinados: desempenho, digestibilidade das rações, características da carcaça e qualidade da carne. 2005. 76p. Dissertação (Mestrado) - Escola Superior de Agricultura Luiz de Queiroz, Piracicaba. 
SAS INSTITUTE. SAS/STAT: guide for personal computer: version 9.1. Cary: SAS Institute, 2003. 235p.

SUSIN, I. Potencial produtivo de ovinos Santa Inês confinados e alimentados com rações de alta proporção de concentrado. 2003. 105p. Tese (Livre Docência) - Escola Superior de Agricultura Luiz de Queiroz, Piracicaba.

URANO, F.S.; PIRES, A.V.; SUSIN, I.; MENDES, C.Q.; RODRIGUES, G.H.; ARAUJO, R.C. de; MATTOS, W.R.S. Desempenho e características da carcaça de cordeiros confinados alimentados com grãos de soja. Pesquisa Agropecuária Brasileira, v.41, p.1525-1530, 2006.
VAN SOEST, P.J.; MASON, V.C. The influence of the Maillard reaction upon the nutritive value of fibrous feeds. Animal Feed Science and Technology, v.32, p.45-53, 1991.

ZINN, R.A.; BARRERAS, A.; CORONA, L.; OWENS, F.N.; WARE, R.A. Starch digestion by feedlot cattle: predictions from analysis of feed and fecal starch and nitrogen. Journal of Animal Science, v.85, p.1727-1730, 2007.

ZINN, R.A.; OWENS, F.N.; WARE, R.A. Flaking corn: processing mechanics, quality standards, and impacts on energy availability and performance of feedlot cattle. Journal of Animal Science, v.80, p.1145-1156, 2002.

Recebido em 19 de fevereiro de 2008 e aprovado em 27 de agosto de 2008 